\title{
Sex Ratio at Birth: A Retrospective Audit of the Birth Records of a Nigerian Hospital
}

\author{
Onyiriuka AN ${ }^{1}$, Ikeanyi EM ${ }^{2}$ \\ ${ }^{1}$ Endocrine and Metabolic Unit, Department of Child Health, University of Benin Teaching Hospital, Benin City, Edo \\ State, Nigeria, ${ }^{2}$ Department of Obstetrics and Gynaecology, College of Health Sciences, Niger Delta University, Wilber- \\ force Island, Bayelsa State, Nigeria.
}

Received: December 05, 2014; Accepted: April 12, 2015

Aims: The aim was to determine the sex ratio at birth in St Philomena Catholic Hospital (SPCH), Benin City, south-south, Nigeria and to assess its relationship with birth order and maternal age.

Methods: In this retrospective cohort study, the records of all deliveries at St Philomena Catholic Hospital (SPCH), Benin City, Nigeria between 1st January, 2005 and 31st December, 2014 (10 years) were retrieved and analyzed. Stillbirths and infants with ambiguous genitalia were excluded in the analysis.

Results: The total number of live-births during the 10-year period under review was 13,702 and these consisted of 7,007 males and 6,695 females, resulting in a sex ratio of 104.7:100 (approximately 1.05) at birth. The yearly sex ratios varied from 1.01 to 1.14 . The maternal age and the birth order significantly influenced offspring sex ratio at birth $(p<0.001)$. The highest sex ratio was found among third-birth-order offspring and the lowest was found among offspring of fifth-birth order and above. Offspring of mothers aged 25-29 years had the highest sex ratio and those of mothers aged 40 years and above had the lowest sex ratio.

Conclusions: The sex ratio at birth in south-south Nigeria is comparable to values obtained from south-west Nigeria but lower than that obtained from north-west Nigeria. The birth order and maternal age influenced the offspring sex ratio at birth.

Keywords: birth order; maternal age; sex ratio.

\section{INTRODUCTION}

The phrase 'sex ratio at birth' (SRB) refers to the number of male live-births for every 100 female births. ${ }^{1}$ The SRB affects several critical demographic measures, such as the 'doubling time' of a population as well as the sex composition of a population. ${ }^{2}$ Data related to SRB are necessary to understanding trends in infant morbidity and mortality, such as low birth weight, prematurity and sudden infant death syndrome. ${ }^{3,4}$ Some researchers have used SRB to assess the impact of environmental factors on the endocrine system and reproductive health of humans. ${ }^{5-9}$ Thus, SRB represents a simple, cheap and noninvasive method studying and monitoring the reproductive status of a population.

Sex ratio at birth varies not only from one country to another but also, within the same country and it may be skewed by factors such as age of the mother, birth order and sex-selective abortions. ${ }^{10}$ Environmental

\section{CORRESPONDENCE}

Dr Alphonsus N. Onyiriuka

Department of Child Health,

University of Benin Teaching Hospital,

PMB 1111, Benin City, Nigeria

E-mail: alpndiony@yahoo.com exposure to endocrine-disrupting compounds may lower sex ratio at birth. ${ }^{11,12}$ Thus, SRB has been regarded as a marker of paternal endocrine disruption. ${ }^{11}$ Worldwide, estimates indicate that SRB is $105-107$ male births for every 100 female births with a median of 105.9. ${ }^{1}$ This median figure is usually used as the baseline for measuring deviations in the sex ratio. Previous studies in Nigeria found a sex ratio of 1.12, 1.04 and 1.05 in the north-west, ${ }^{13}$ the south-east, ${ }^{14}$ and the south-west, ${ }^{15}$ respectively. To the best of our knowledge, there is no report of SRB from south-south, Nigeria. Secular trends in SRB have been reported from different regions and countries of the world. ${ }^{5,8,11}$ The above considerations prompted the present study.

The purpose of the present study is to determine the sex ratio at birth in Benin City, south-south Nigeria and assess its relationship with birth order and maternal age.

\section{METHODS}

A retrospective assessment of the birth records of all the deliveries at St Philomena Catholic Hospital 
(SPCH), Benin City, Nigeria between 1st January, 2005 and 31st December, 2014 (10 years) was carried out. Stillbirths were excluded in the analysis in conformity with the definition of sex ratio at birth. ${ }^{1}$ Infants with ambiguous genitalia were also excluded from the analysis. The deliveries were recorded according to the month and year of delivery. The study design was approved by the hospital authority. The sex ratio at birth was computed, using the formula $\mathrm{B} / \mathrm{G} \times 100$ (where ' $\mathrm{B}$ ' is number of male births and ' $G$ ' is number of female births). In this study, a birth order refers to the proband's position within his/her sibship.

Statistical analysis was performed using the statistical package for social sciences (SPSS, version 16.0). Descriptive statistics such as frequencies, means, standard deviations (SDs), confidence intervals (CIs) and percentages were used to describe all the variables. Students' $t$ test was used in ascertaining the significance of differences between two means with p-value set at $<0.05$.

\section{RESULTS}

During the 10 years covered by this review, a total of 13,702 live-births were recorded at SPCH and this consisted of 7,007 males and 6,695 females. Males accounted for $51.1 \%$ of the total live- births. A quarter $(24.9 \%)$ of the total births were recorded in the years 2013 and 2014. The overall sex ratio for the 10 years pooled together was 1.046 (approximately $1.05)$.

\begin{tabular}{lllll}
\hline $\begin{array}{l}\text { Table 1. Annual live-births according to gender and sex } \\
\text { ratio (2005-2014). }\end{array}$ \\
\hline $\begin{array}{l}\text { Year of } \\
\text { Study }\end{array}$ & Total & $\begin{array}{l}\text { Number } \\
\text { of males }\end{array}$ & $\begin{array}{l}\text { Number } \\
\text { of females }\end{array}$ & $\begin{array}{l}\text { Sex } \\
\text { ratio }\end{array}$ \\
2005 & 1128 & 569 & 559 & 1.02 \\
2006 & 1487 & 764 & 723 & 1.06 \\
2007 & 1304 & 659 & 645 & 1.02 \\
2008 & 1230 & 647 & 583 & 1.11 \\
2009 & 1304 & 660 & 644 & 1.02 \\
2010 & 1332 & 690 & 642 & 1.07 \\
2011 & 1105 & 588 & 517 & 1.14 \\
2012 & 1398 & 714 & 684 & 1.04 \\
2013 & 1653 & 829 & 824 & 1.01 \\
2014 & 1761 & 887 & 874 & 1.01 \\
$2005-14$ & 13,702 & 7007 & 6695 & 1.05 \\
\hline
\end{tabular}

As shown in Table 1, the highest sex ratio of 1.14 was recorded in the year 2011. The lowest sex ratio was
1.01 and this was recorded in two successive years (2013 and 2014). We evaluated whether the SRB has changed overtime and observed that the percentage of male births increased from 50.4\% (95\% CI $=49.2$ $51.6)$ in 2005 to $52.6 \%(95 \% \mathrm{CI}=51.4-53.8)$ in 2008 and then dropped to $50.6 \%(95 \% \mathrm{CI}=49.4-51.8)$ in 2009. Subsequently, the proportion of male births rose to a peak of $53.2 \%(95 \% \mathrm{CI}=52.0-54.4)$ in 2011 . From 2012 to 2014 the percentage of male births remained relatively low, varying from $50.1 \%$ in 2012 to $50.4 \% 2014$ (Table 1). However, no clear trend was apparent in these comparisons except that the proportion of male births have been low in the past three years (2012 to 2014).

\begin{tabular}{|c|c|c|c|c|c|c|}
\hline \multirow{2}{*}{$\begin{array}{l}\text { Year } \\
\text { of study }\end{array}$} & \multirow{2}{*}{$\begin{array}{l}\text { Yearly } \\
\text { total }\end{array}$} & \multicolumn{5}{|c|}{ Sex ratio by birth order } \\
\hline & & 1st & 2nd & $3 \mathrm{rd}$ & 4 th & $\geq 5$ th \\
\hline 2005 & 1128 & 1.04 & 1.03 & 1.07 & 1.02 & 1.01 \\
\hline 2006 & 1487 & 1.04 & 1.04 & 1.06 & 1.03 & 1.02 \\
\hline 2007 & 1304 & 1.03 & 1.05 & 1.05 & 1.04 & 1.03 \\
\hline 2008 & 1230 & 1.04 & 1.06 & 1.09 & 1.05 & 1.04 \\
\hline 2009 & 1304 & 1.03 & 1.03 & 1.05 & 1.04 & 1.03 \\
\hline 2010 & 1332 & 1.02 & 1.03 & 1.04 & 1.04 & 1.01 \\
\hline 2011 & 1105 & 1.04 & 1.06 & 1.14 & 1.08 & 1.05 \\
\hline 2012 & 1398 & 1.02 & 1.03 & 1.05 & 1.03 & 1.01 \\
\hline 2013 & 1653 & 1.01 & 1.02 & 1.03 & 1.02 & 1.00 \\
\hline 2014 & 1761 & 1.01 & 1.01 & 1.03 & 1.02 & 1.01 \\
\hline 2005-14 & 13702 & 1.03 & 1.04 & 1.05 & 1.03 & 1.02 \\
\hline
\end{tabular}

As depicted in Table 2, the highest sex ratio was found in the third-birth-order offspring and lowest sex ratio was found among offspring of fifth rank order and above.

\begin{tabular}{|c|c|c|c|c|}
\hline \multicolumn{5}{|c|}{$\begin{array}{l}\text { Table } 3 . \text { Sex ratio of offspring at birth according t } \\
\text { maternal age groups. }\end{array}$} \\
\hline $\begin{array}{l}\text { Maternal } \\
\text { age } \\
\text { in years }\end{array}$ & Total & $\begin{array}{l}\text { Number } \\
\text { of males }\end{array}$ & $\begin{array}{l}\text { Number } \\
\text { of females }\end{array}$ & $\begin{array}{l}\text { Sex } \\
\text { ratio }\end{array}$ \\
\hline$<20$ & 397 & 202 & 195 & 1.04 \\
\hline $20-24$ & 2378 & 1216 & 1162 & 1.05 \\
\hline $25-29$ & 5148 & 2657 & 2491 & 1.07 \\
\hline $30-34$ & 3688 & 1893 & 1795 & 1.05 \\
\hline $35-39$ & 1570 & 798 & 772 & 1.03 \\
\hline$\geq 40$ & 245 & 124 & 121 & 1.02 \\
\hline Unknown & 276 & 140 & 136 & 1.03 \\
\hline Total & 13,702 & 7007 & 6695 & 1.05 \\
\hline
\end{tabular}

Table 3 showed that the offspring sex ratio was highest among mothers aged 25-29 years and lowest among offspring of mothers aged 40 years and above. 
The overall average maternal age was $27.3 \pm 4.1$ years (95\% CI $=27.2-27.4)$.

\begin{tabular}{|c|c|c|c|}
\hline Parameter & $\begin{array}{l}\text { Male births } \\
(\mathrm{n}=7007)\end{array}$ & $\begin{array}{l}\text { Female births } \\
(\mathrm{n}=6695)\end{array}$ & $\begin{array}{l}\text { t-statistic } \\
\text { (p-value) }\end{array}$ \\
\hline $\begin{array}{l}\text { Mean } \\
\text { maternal } \\
\text { age (years)* }\end{array}$ & $27.2 \pm 3.1$ & $28.0 \pm 3.6$ & $\begin{array}{l}9.716 \\
(<0.001)\end{array}$ \\
\hline $\begin{array}{l}\text { Mean birth } \\
\text { order }\end{array}$ & $2.6 \pm 1.2$ & $3.1 \pm 1.1$ & $\begin{array}{l}17.777 \\
(<0.001)\end{array}$ \\
\hline
\end{tabular}

Number of unknown maternal age $=276 . *$ Mean maternal age: Number of male births $=6,866$; number of female births $=6,560$; Sex ratio $=1.046$ (approximately 1.05 ).

Table 4 showed that the maternal age and the birth order significantly influenced offspring sex ratio at birth.

\section{DISCUSSION}

Our data indicate that the offspring sex ratio at birth in the total sample studied was 1.05 . This is in complete agreement with 1.05 previously reported from south-west, Nigeria ${ }^{15}$ but slightly higher than 1.04 found in south-east, Nigeria. ${ }^{14}$ Thus, suggesting that over the years, there has been no significant change in sex ratio at birth in southern Nigeria. In contrast, the sex ratio found in the present study was significantly lower than 1.12 reported from northern Nigeria about a decade ago. ${ }^{13}$ Garenne in a review of 56 surveys, totaling 1.130 million births in African countries found that the average sex ratio was 1.033 (approximately 1.03). ${ }^{16}$ The reason for the lower sex ratio found in our study compared with that found in northern Nigeria is not clear. One obvious difference between northern and southern Nigeria is climatic, with the north being generally hotter and with less rainfall compared with the south. It is, therefore, possible that more males are born in the relatively hotter north compared with the south of Nigeria. This view is supported by reports of some studies from Finland which indicated that more males are born in years with higher mean annual temperatures. ${ }^{17-19}$ The result of another study also suggests that more males are born during warmer periods. ${ }^{20}$ In contrast, Dixson et $a 1,{ }^{21}$ in a study in New Zealand, found that the ambient temperature did not influence the proportion of males at birth. However, they noted that temperature may influence human sex ratio at birth but that such effects of temperature are not universal. The reason for the conflicting results is not clear but suggests that other unidentified environmental factors may play a role. The SRB (1.05) found in the present study is slightly less than the worldwide median of 105.9 (approximately 1.06). ${ }^{1}$ There is no readily available explanation for this difference.

Data from the present study indicate that the birth of a male offspring was significantly more frequent among lower-birth-order offspring compared with higher-birth-order offspring. Births of fifth rank order and above had the lowest sex ratio. Our finding is in consonance with the report of previous studies ${ }^{22,23}$ and suggests that births of lower rank order have higher proportions of males than those of higher ranks. In contrast, other researchers reported that there was no association between birth order and sex ratio. ${ }^{24}$ In that study, the study population was 6,689 which was significantly lower than 13,702 used in the present study. A large sample size is known to be more ideal for a sex ratio study. Indeed, in a review of the literature, James stated that in general, results of small-sample studies have been inconclusive and contradictory. ${ }^{25}$ Novitski and Kimball, using a large sample size $(3,645,750)$, found a significant association between birth order and sex ratio. ${ }^{26}$ On the other hand, the conflicting reports may suggest that unidentified environmental factors may influence the sex ratio rather than demographic factors alone. We do not have any readily available explanation for the higher male births at the third birth-order offspring. It might mean that the female reproductive system is physiologically at its best for survival of male embryos during the third-birth-order pregnancy.

In the present study, male births were significantly more frequent in younger mothers compared with older mothers. We found the highest sex ratio was among mothers aged 24-29 years. Thus, suggesting that younger women tend to have a higher frequency of male births. This view is supported by the report of Rueness et al. ${ }^{27}$ They proposed that a higher maternal age serves as a stressor to the female reproductive system during pregnancies due to physical aging. There is some evidence that male embryos are more vulnerable to such stressors in early developmental stages, putting them at a relatively higher risk of early intrauterine death compared with female embryos. ${ }^{27}$ Indeed, Hassold et al. ${ }^{28}$ found that fetal death rate was higher for male than female fetuses and it is estimated that the increase is about $30 \%$ in chromosomally normal spontaneous abortions. In 
contrast, Maconochie et al did not find any evidence that maternal age influenced sex ratio at birth. ${ }^{29}$

Large study population which is ideal for studies on sex ratio at birth was the strength of the study. One limitation is that the recorded maternal ages may be inaccurate and this may affect assessment of the association between maternal age and offspring sex ratio. We also did not explore the possibility that male births may be heritable in families.

\section{CONCLUSIONS}

The sex ratio at birth in south-south Nigeria is comparable to values obtained from south-west

\section{REFERENCES}

1. Hesketh T, Xing WZ. Abnormal sex ratio in human populations: causes and consequences. Proc Natl Acad Sci, USA. 2006;103(36):13271-75

2. Markle GE. Sex ratio at birth: values, variance, and some determinants. Demography. 1974;11:131-42.

3. Stevenson DK, Verter J, Fanaroff AA, Oh W, Ehrenkranz RA, Shankaran S, et al. Sex differences in outcomes of very low birthweight infants: the newborn male disadvantage. Arch Dis Child Fetal Neonatal Ed. 2000;83:182-5.

4. Getahun D, Amre D, Rhoads GG, Demissie K. Maternal and obstetric risk factors for sudden infant death syndrome in the United States. Obstet Gynecol. 2004;103(4):646-52.

5. Davis DL, Gottlieb M, Stampnitzky J. Reduced ratio of male to female births in several industrial countries: a sentinel health indicator? JAMA. 1998;279(13):1018-23.

6. Yoshimura T, Kaneko S, Hayabuchi H. Sex ratio in offspring of those affected by doxin and doxin-like compounds: the Yucho, Seveso, and Yucheng incidents. Occup Environ Med. 2001;58:540-1.

7. Toppari J, Shakkebaek NE. Sexual differentiation and environmental endocrine disrupters. Baillieres Clin Endocrinol Metab. 1998;12:143-56.

8. Martuzzi M, Di Tanno ND, Bertollini R. Declining trends of male proportion at birth in Europe. Arch Environ Health. 2001;56:358-64.

9. Mizuno R. The male/female ratio of fetal deaths and births in Japan. Lancet 2000;356:738-9.

10. Matthews TJ, Hamilton BE, Division of Vital Statistics. Trend analysis of the sex ratio at birth in the United States. National Vital Statistics Reports, Vol 53, issue 20, 2005.

11. James WH. Offspring sex ratios at birth as markers of paternal endocrine disruption. Environ Res. 2006;100:77-85.

12. Grech V, Vassallo-Agius P, Savona-Ventura C. Secular trends in sex ratio at birth in North America and Europe over the second half of the $20^{\text {th }}$ century. J Epidemiol Comm Health. $2003 ; 57: 612-5$.

13. Sule ST, Madugu HN. Sex ratio at birth in Zaria, Nigeria. Ann Hum Biol. 2004;31(2):258-62.

14. Egwuatu VE. The sex ratio of Igbo births. Int J Gynecol Obstet. 1984;22:399-402
Nigeria but lower than that obtained from north-west Nigeria. The birth order and maternal age influenced the offspring sex ratio at birth.

\section{ACKNOWLEDGEMENTS}

We are grateful to the hospital administrators for granting us access to the hospital's delivery records.

\section{DISCLOSURE}

The authors report no conflicts of interest in this work. No violation of human rights and safety.

Funding: Nil

15. Azeez MA, Akinboro A, Bakare AA. Human sex ratio at birth in southwest Nigeria. Indian J Hum Genet. 2007;13(2):59-64.

16. Garenne M. Sex ratio at birth in African populations: a review of survey data. Hum Biol. 2002;74:889-900.

17. Helle S, Helama S, Lertola K. Evolutionary ecology of human birth sex ratio under the compound influence of climate change, famine, economic crises and wars. J Anim Ecol 2009;78:1226-33.

18. Catalano R, Brucker T, Smith KR. Ambient temperature predicts sex ratio and male longevity. Proc Natl Acad Sci USA. 2008;105:2244-7.

19. Helle S, Helama S, Jokela J. Temperature-related birth sex ratio bias in historical Sami: warm years being more sons. Biol Letters. 2008;4:60-2.

20. McLachlan TC, Storey H. Hot male: can sex in humans be modified by temperature? J Theor Biol. 2003;222:71-2.

21. Dixson BJ, Haywood J, Lester PJ, Ormsby DK. Whatever the weather: ambient temperature does not influence the proportion of males born in New Zealand. PLosONE 6(9):e25064.

22. Branum A, Parker J, Schoendorf K. Trends in US sex ratio by plurality, gestational age, and race/ethnicity. Hum Reprod. 2009;24(11):2936-44.

23. Orvos H, Kozinsky Z, Bartfai G. Natural variation in the human sex ratio. Hum Reprod. 2001;16:803.

24. Nixon NN. Maternal age at birth delivery, birth order and secondary sex ratio in the Old Order Amish of Lancaster County. MSc Thesis submitted to the Graduate School of the University of Massachusetts, Amherst, 2013.

25. James WH. Sex ratio of offspring and the causes of placenta pathology. Hum Reprod. 1995;10:1405-6.

26. Novitski E, Kimball AW. Birth order, parental ages, and sex of offspring. Am J Hum Genet. 1958;10(3):268-75.

27. Rueness J, Vatten L, Eskild A. The human sex ratio: effects of maternal age. Hum Reprod. 2012;27(1):283-7.

28. Hassold T, Quillen SD, Yumane JA. Sex ratio in spontaneous abortions. Ann Hum Genet. 1983;47:39-47.

29. Maconochie N, Roman E. Sex ratio: are there natura variations within the human population? Brit J Obstet Gynaecol. 1997;104:1050-3. 